\title{
In Vitro Study on the Antimicrobial Activity of Curcuma longa Rhizome on Some Microorganism
}

\author{
Mbah-Omeje, Kelechi Nkechinyere* \\ Department of Applied Microbiology and Brewing, Enugu State University of Science and Technology, Enugu State, Nigeria \\ Email address: \\ kelechimbahomeje@gmail.com(K. Nkechinyere) \\ ${ }^{*}$ Corresponding author \\ To cite this article: \\ Mbah-Omeje, Kelechi Nkechinyere. In Vitro Study on the Antimicrobial Activity of Curcuma longa Rhizome on Some Microorganism. \\ American Journal of Biomedical and Life Sciences. Vol. 7, No. 1, 2019, pp. 1-5. doi: 10.11648/j.ajbls.20190701.11
}

Received: November 23, 2018; Accepted: December 20, 2018; Published: February 15, 2019

\begin{abstract}
The present study investigates the antimicrobial activity, phytochemical and minimum inhibitory concentration (MIC) of Curcuma longa rhizome extract on Staphylococcus aureus, Staphylococcus epidermidis and Streptococcus salivarius. Methanol, and chloroform extracts of the plant rhizome were collected and obtained by standard methods. All the solvent extracts were evaporated to dryness, dry residues were dissolved in dimethyl sulfoxide (DMSO) and tested for antibacterial activity. The plant extract was distinctively applied as antibacterial agent through agar well diffusion method on aseptically prepared nutrient agar. It was determined in the result of this study, that the chloroform extract of Curcuma longa rhizome was found to show more activity than the methanol extract on all the isolates. The inhibition zone diameter (IZD) of the chloroform extracts ranged between $7-34 \mathrm{~mm}$ while ethanol extract ranged between $3-13 \mathrm{~mm}$. The MIC varied between $1.56-3.125 \mathrm{mg} / \mathrm{ml}$ and $1.56-6.25 \mathrm{mg} / \mathrm{ml}$ for methanol and chloroform extract respectively while Staphylococcus epidermid is showed the least sensitivity of all the isolates The chloroform extracts exhibited higher inhibitory activity on the test organisms than the positive control ciprofloxacin. Phytochemical analyses of the extracts revealed the presence of alkaloids, tannins, phenolic compounds, terpenoids, saponins and flavonoids. According to this study, Curcuma longa rhizome can be used for the treatment of diseases caused by Staphylococcus sppas well as Streptococcus salivarius.
\end{abstract}

Keywords: Curcuma Longa, Staphylococcus Aureus, Staphylococcus Epidermidis, Streptococcus Salivarius, Extracts

\section{Introduction}

The clinical efficacy of many existing antibiotics is being threatened by the multidrug-resistant pathogens [1]. The increasing failure of chemotherapeutic and antibiotic resistance exhibited by pathogenic microbial agents has led to the screening of several medicinal plants for their potential antimicrobial activity [2], [3]. The use of plant extracts in the treatment of diseases have become of important interest over the years [1]. Medicinal plants generally contain a number of compounds, which may be potential natural antibacterial for the treatment of common bacterial infections [11]. Curcuma longa (turmeric) is a rhizomatous herbaceous perennial plant of the ginger family. Tumeric is a spice that has received much interest from both the medical/scientific worlds as well as from the culinary world. Turmeric is a natural medicament with a wide spectrum of biologic actions which include anti- inflammatory, antioxidant, anti-carcinogenic, antimutagenic, anticoagulant, antidiabetic, infertility, antibacterial and antifungal activities [4]. Components of turmeric are namedcurcuminoids [5]. These components are polyphenols with a strong antioxidant function [30]. Curcumin, (diferuloylmethane) the main yellow bioactive component of turmeric has a wide spectrum of biological actions and this provides a basis for exploring its endodontic applications. Aromatic tumerone is another bioactive compound found in turmeric and recently is a promising player in regeneration of neurological diseases [31]. The aim of the study was to evaluate the bactericidal property of turmeric extract as alternative to synthetic antibiotics and to determine the minimum inhibitory concentration as well as the phytochemical contents of Curcuma longa extract. 


\section{Materials and Methods}

\subsection{Collection of Plant Materials}

Turmeric rhizomes were purchasedfrom Ogbete main market, Enugu State and authenticated at Biology department, Enugu State University of Science and Technology. The collected rhizomes were washed thoroughly and shade dried. The dried plant material was finely powdered and grounded using sterile blender.

\subsection{Preparation of Turmeric Extract}

\subsubsection{Methanol Extract}

$200 \mathrm{~g}$ of air-driedpowderedCurcuma longa rhizomewas weighed and mixed in 1L of methanol. The mixture wasleftat room temperature for 7 days for maceration, with daily intermittent shaking. After 7 days, the solution was filtered using mushin clothand the filtratesevaporated to dryness using a rotary evaporator at $40^{\circ} \mathrm{C}$. They were stored at $20^{\circ} \mathrm{C}$ until use.

\subsubsection{Chloroform Extract}

$100 \mathrm{~g}$ of the air dried powderedCurcuma longa rhizome was weighed using weighing balance and dispensed in $500 \mathrm{ml}$ of chloroform. The mixture was leftat room temperature for 7 days for maceration, with daily intermittent shaking. After 7 days, the solution was filtered using mushin cloth and the filtrates evaporated to dryness using a rotary evaporator at $40^{\circ} \mathrm{C}$. They were stored at $20^{\circ} \mathrm{C}$ until use.

\subsection{Collection of the Selected Microorganisms}

The test organisms were collected from the medical laboratory of microbiology and parasitological unit of the University of Nigeria teaching Hospital, (UNTH Enugu).

\subsection{Antibacterial Activity Assay}

Antibacterial activity of methanol and chloroform extracts of Curcuma longawas determined by agar-well diffusion method.

\section{Agar-Well Diffusion Method}

The antimicrobial screening was carried out using the agar well diffusion method as described by Lino and Deogracious, 2006. The test isolates were separately inoculated into the prepared nutrient agar plates. A sterile cork borer was then used to make four wells ( $6 \mathrm{~mm}$ diameter each) for different concentrations of the extract on each of the plates containing cultures of different test isolate. The different concentrations of $25,50,100$, and $200 \mathrm{mg} / \mathrm{ml}$ of the extracts were then introduced into the four wells using sterile Pasteur pipettes. A known antibiotic was used to test bacteria isolates susceptibility to antibiotics. This was used to compare and contrast the anti-microbial activities of the plant extract. The culture plates were allowed to stand on the working bench for $30 \mathrm{~min}$ for pre diffusion and were then incubated at $37^{\circ} \mathrm{C}$ for 24h. After $24 \mathrm{~h}$, antibacterial activity was determined by measuring the diameter zones of inhibition ( $\mathrm{mm}$ ) (against the test isolate) around each of the extract and antibiotic.

\subsection{Phytochemical Analysis of the Plant Extract}

Phytochemical screening tests were carried out on the methanol extract of Curcuma longa according to methods used by Uthayarasa, 2010; the test sample was subjected to phytochemical analysis in order to determine the presence of phytochemical constituents. The phytochemical tests employed were for tannins, saponin, reducing sugar, flavonoids and terpenoids.

\subsubsection{Test for Tannins}

\section{Lead test}

$20 \mathrm{mg}$ of turmeric was dissolved in $1 \mathrm{ml}$ of distilled water and heated on a water bath. The mixture was then filtered and3 drops of Ferric chloride were added to the solution. A green color indicated the presence of tannins on the extract.

\subsubsection{Test for Saponins}

\section{Frothing test}

$40 \mathrm{mg}$ of turmeric was dissolved with $5 \mathrm{ml}$ of distilled water and shaken vigorously till a stable persistent froth was obtained. The froth was mixed with 3 drops of olive oil and shaken vigorously.

The presence of emulsion indicated its presence on the extract.

\subsubsection{Test for Terpeniods}

Salkowaski's test

$20 \mathrm{mg}$ of turmeric was dissolved in $1 \mathrm{ml}$ of chloroform and $1 \mathrm{ml}$ of concentrated sulphuric acid was added to it. A reddish brown discoloration at the interface showed the presence of terpenoids.

\subsubsection{Test for Reducing Sugar}

\section{Fehling's test}

Few drops of extract were heated with Fehling's A and B solution. The appearance of orange red precipitate showed the presence of carbohydrates.

\subsubsection{Test for Flavoniods \\ Ferric chloride test}

$20 \mathrm{mg}$ of turmeric was dissolved in $1 \mathrm{ml}$ of distilled water. $0.5 \mathrm{ml}$ of dilute ammonia solution and Conc. Sulphuric acid was added later. A yellow color showed the presence of flavonoids. The yellow color became colorless on allowing the solution to stand.

\subsection{Determination of Minimum Inhibitory Concentration (MIC) of the Plant Extract}

Minimum inhibitory concentration was determined by agar well diffusion method as described by Ogata et al. (2000). The concentrations used in the antimicrobial susceptibility test were diluted further ( 2 fold-dilution) to get different concentrations of $12.5,6.25,3.125$, and $1.5625 \mathrm{mg} / \mathrm{ml}$, which were incorporated into various test tubes. $0.1 \mathrm{ml}$ of the test organism previously diluted to 0.5 Mcfarland turbidity standard was introduced and spread into each plate containing Muller Hinton agar.6mm wells were cut using sterilized cork borer and each filled with $0.1 \mathrm{ml}$ of extracts. The plates were 
incubated at $37^{\circ} \mathrm{C}$ for $24 \mathrm{~h}$ and the diameter of resultant zone of inhibition was measured. The least concentration of the extacts that inhibits the growth of the test organism weredesignated as the minimum inhibitory concentration.

\section{Results}

\subsection{Antimicrobial Activity of Methanol Extract of Curcuma longa on Isolates}

The methanol extract of curcuma longa exhibited various antibacterial activities against Staphylococcus aureus, Staphylococcus epidermidis, and Streptococcus salivarius. At the highest concentration of $200 \mathrm{mg} / \mathrm{ml}$ Streptococcus salivariusshowed the highest average zone of inhibition (9.0mm) (Table 1).

\subsection{Antimicrobial Activity of Chloroform Extract of Curcuma longa on Isolates}

The test organisms were inhibited by chloroform extract at concentrations of $200-50 \mathrm{mg} / \mathrm{ml}$. At the highest concentration of $200 \mathrm{mg} / \mathrm{ml}$, Streptococcus salivarius showed the highest average zone of inhibition at $34 \mathrm{~mm}$, Staphylococcus aureus (16mm), and Staphylococcus epidermidis $(7 \mathrm{~mm})$ whileStaphylococcus epidermidisshowed no inhibition at $25 \mathrm{mg} / \mathrm{ml}$ (Table 2).

\subsection{Minimum Inhibitory Concentration (MIC) of Curcuma longa Extracts}

Table 3 and 4 shows the minimum inhibitory concentration of methanol and choloformCurcuma longa extract on the test organisms. The methanol and chloroform extracts showed similar results, the least concentration that inhibited the growth of Staphylococcus aureusandStreptococcussalivarius was $1.56 \mathrm{mg} / \mathrm{ml}$ while the least concentration that inhibited the growth of Staphylococcus epidermidis was $3.125 \mathrm{mg} / \mathrm{ml}$ and $6.25 \mathrm{mg} / \mathrm{ml}$ for methanol and chloroform extracts respectively.

Table 1. Zone of Inhibition ( $\mathrm{mm}$ ) of Methanol Extract of Curcuma longaon Isolates. Extract inhibitory concentration (mg/ml).

\begin{tabular}{lllll}
\hline Test organisms & $\mathbf{2 0 0}$ & $\mathbf{1 0 0}$ & $\mathbf{5 0}$ & $\mathbf{2 5}$ \\
\hline Staphylococcus aureus & 8.0 & 4.0 & 3.0 & 3.0 \\
Streptococcus salivarius & 9.0 & 5.0 & 4.0 & 3.0 \\
Staphylococcus epidermidis & 7.0 & 12.0 & 4.0 & - \\
\hline
\end{tabular}

KEY: - =No inhibition, CIPX=Ciprofloxacin

Table 2. Zone of inhibition ( $\mathrm{mm}$ ) of chloroform extract of Curcuma longa on isolatesExtract inhibitory concentration (mg/ml).

\begin{tabular}{llllll}
\hline Test organisms & $\mathbf{2 0 0}$ & $\mathbf{1 0 0}$ & $\mathbf{5 0}$ & $\mathbf{2 5}$ & 12.0 \\
\hline Staphylococcus aureus & 16.0 & 14.0 & 13.0 & 20.0 & 13.0 \\
Streptococcus salivarius & 34.0 & 23.0 & 1.0 & - & 19.0 \\
Staphylococcus epidermidis & 13.0 & 3.0 & 17.0 & - \\
\hline
\end{tabular}

KEY: - =No inhibition, CIPX=Ciprofloxacin

Table 3. Minimum Inhibitory Concentration (MIC) of Curcuma longa Methanol extract. Extract inhibitory Concentration.

\begin{tabular}{llllll}
\hline Test Organisms & $\mathbf{2 5}$ & $\mathbf{1 2 . 5}$ & $\mathbf{6 . 2 5}$ & $\mathbf{3 . 1 2 5}$ & $\mathbf{1 . 5 6}$ \\
\hline Staphylococcus aureus & - & - & - & - & - \\
Streptococcus & - & - & - & 1.56 & + \\
Salivarius & & - & - & + & + \\
Staphylococcus epidermidis & - & - & - & + \\
\hline
\end{tabular}

Key: + Visible turbidity signifying growth, - No visible turbidity.

Table 4. Average Minimium Inhibitory Concentration (MIC) of Curcuma longa Chloroform extract. Extract inhibitory Concentration.

\begin{tabular}{|c|c|c|c|c|c|c|}
\hline Test Organism & 25 & 12.5 & 6.25 & 3.125 & 1.56 & MIC (mg/ ml) \\
\hline Staphylococcus aureus & - & - & - & - & + & 1.56 \\
\hline $\begin{array}{l}\text { Streptococcus } \\
\text { Salivarius }\end{array}$ & - & - & - & - & + & 1.56 \\
\hline Staphylococcus epidermidis & - & - & + & + & + & 6.25 \\
\hline
\end{tabular}

Key: + Visible turbidity signifying growth, - No visible turbidity.

\subsection{Phytochemical Analysis of Curcuma longa}

The preliminary phytochemical analysis of methanol extract of Curcuma longa showed presence of some important Phytochemicals like alkaloids, tannins, phenolic compounds, terpenoids, saponins and flavonoids. These phytoconstituents have important pharmacological activities like anti mutagenic, anti-inflammatory, antibacterial, antiprotozoal, and antioxidant properties (Table 5). 
Table 5. Phytochemical Analysis of Methanol Extract of curcuma longa Rhizomes.

\begin{tabular}{llll}
\hline Phytochemical & Test & Observation & Inference \\
\hline Alkaloids & Wagner's test & Red precipitate & Green colour \\
Tannins and Phenolic compounds & Lead test & Reddish-brown colour \\
Terpenoids and Phytosterols & Salkowaski's test & Presence of emulsion & + \\
Saponins & Foam test & White precipitate & + \\
Flavonoids & Ferric chloride test & - & + \\
Glycosides & Brown ring & - & + \\
Carbohydrate & Fehling's test & + \\
\hline
\end{tabular}

\section{Discussion}

Over the years, plants and plant materials have been used in the treatment of many diseases and infections. In the present study, the chloroform and methanol extracts of Curcuma longa exhibited different ranges of activity against S. aureus, Streptococcus salivariusand Staphylocococcus epidermidis (Tables1 and 2) indicating that the plant extracts had broad antibacterial spectrums [10]. Zones of inhibitions produced by chloroform and methanol extracts in the present study ranged between $7 \mathrm{~mm}-34 \mathrm{~mm}$. The data obtained showed that the inhibitory effects on the various tested organisms were dose-dependent. This is in agreement with the work of Gupta et al. (2015) who reported that fractions of C. longa rhizome had an inhibitory effect onS. aureus with zone diameter between $8 \mathrm{~mm}$ and $16 \mathrm{~mm}$. Chandrana et al. (2010) and Kim et al. (2012) also reported that turmeric extract was effective against E.coli, Bacillus subtilisand $S$. aureus which may be due to the presence of curcuminiod, a phenolic compound. Also Negi et al. (1999) reported that tumerone and curlone components of turmeric possessed better antibacterial activity against a wide range of microbes including Bacillus subtilis, Bacillus coagulans, E.coli, Staphylococcus aureusand Pseudomonas aeruginosa. Cikricki et al. (2008); Raiet al. (2008) and Basniwalet al.(2011) also reported that the antimicrobial activity of turmeric could be due to the presence of essential oil, curcumins, turmeric oil, tumerone and veleric acid. From the study, the antimicrobial activity of chloroform compared well with the standard drug ciprofloxacin. This is in agreement with the studies of Negiet al.(1999);Gupta et al. (2015), Parveen and Jehan (2015) who revealed very significant antimicrobial activity with the extracts of $C$. longa rhizome demonstrating broad spectrum of activity against the test organism. The chloroform extracts showed good antibacterial activity with zone of inhibition greater than or equal to $10 \mathrm{~mm}$ indicating good antibacterial activity. Based on the limited spectrum of activity of methanol extracts when compared with the chloroform extracts, it suggests that the active component is more soluble in chloroform than in methanol. Studies have shown that some extracts have the ability to extract more of the essential oils and secondary plant metabolites which are believed to exert antibacterial activity on the test organism $[1,34]$.

The MIC values of the $C$. longa rhizome extracts were similar at $1.56 \mathrm{mg} / \mathrm{ml}$ for S.aureus and Streptococcus salivariuswhile the MIC values for chloroform and methanol extract varied between 3.125 and $6.25 \mathrm{mg} / \mathrm{ml}$ respectively (Tables 3 and 4);thus, indicating that evaluation of MIC is sufficient for measuring bactericidal activity [30].

From the study, the preliminary phytochemical analysis of methanol extract of $C$. longa showed the presence of alkaloids, tannins, phenolic compounds, terpenoids, saponins and flavonoid (Table 5). The phytochemical constituents are responsible for the biological and pharmacological actions of plants. Curcumin, demethoxycurcumin and bis-demethohydroxycurcumin are three pharmacologically important curcuminoids that have been isolated from Curcuma longa [6]. The phytochemical results obtained in the study are similar to those obtained by Ankuret al. (2015). The antimicrobial activity demonstrated by $C$. longa extract could be attributed to the presence of tannins and saponins which have been reported to possess antimicrobial activity [23, 24]. The metabolites such as phenolics, glycosides and flavonoids have been reported to be potent free radical scavengers and antioxidants [24]. The presence of flavonoids and phenolic compounds in $C$. longa rhizome in the study could suggest its antioxidant activity.

\section{Conclusions}

From this study, it was observed that the chloroform extract exhibited higher inhibitory activity on the test organism than the methanol extract and compared well with the standard drug ciprofloxacin. This is significant because of the possibility of incorporating its use against multidrug resistant organisms. The present work has shown phytochemical compositions andantimicrobial activity of $C$. longa rhizome extracts confirming the great potential of bioactive compounds.

\section{References}

[1] C. C. Ugwu, I. M. Ezeonu, K. Mbah-Omeje, C. G. Agu and S. C. Onuorah. Evalution of the antimicrobial effects of Syzygium aromatic (clove) and Garcinakola (bitter kola) extracts singly and in combination, on some bacteria. World $\mathrm{J}$ of Phar and Phar Sci. 6 (12)(2017) 1-13.

[2] R. N. Okigbo and O. O. Ogbonnaya. Antifungal effects of two tropical plant extracts Occimumgratissimum and Afromummelegueta on post harvest yam Discoreaspp rot. African J. Biotech 9 (2006) 727-731.

[3] A. J. Hou, Liu, H. Z. Yang, and H. D. Sun. Hydrolyzable tannins and related polyphenols from Eucalyptus globules. J. Asian Nat Prod . Res 2 (2000) 205-212. 
[4] H. P. Ammon and M. A. Wahl. Pharmacology of Curcuma longa. Planta Medicine. 57 (2010)1-7.

[5] R.. Bundy, A. F. Walker, R. W. Middleton and J. Booth. Turmeric extract may improve irritable bowel syndrome symptomology in otherwise healthy adults: A pilot study. Journal of Alternative and Complementary Medicine. 10 (2004) 1015-1018.

[6] H. Chandrana, S. Baluja and S. V. Chanda. Comparison of antibacterial activities of selected species of Zingiberaceae family and some synthetic compounds. Turkey's Journal of Biological sciences. 29 (2010)83-97.

[7] S. Cikricki, E. Mozioglu and H. Yylmaz. Biological activity of curcuminoids isolated from Curcuma longa. Rec Nat Prod. ;12: (2008)19-24.

[8] M. Cruz-Correa, D. A. Shoskes, and P. Sanchez. Combination treatment with curcumin and quercetin of adenomas in familial adenomatous polyposis. Journal of Clinical Gastroenterol Hepatol. 4 (2006)1035-1038.

[9] S. Gupta and R. Sadhana. A comparison of the antimicrobial activity of garlic, ginger, carrot, and turmeric pastes against Escherichia coli O157:H7 in laboratory buffer and ground beef. Journal of Foodborne Pathogenic Disesaes. 2 (2005) 330-340.

[10] H. Hanaiand K. Sugimoto. Curcumin has bright prospects for the treatment of inflammatory bowel disease. Curr Pharm Des. 15 (2009) 2087-2094.

[11] J. H. Kim, S. C. Gupta, B. Park, V. R. Yadav and B. B. Aggarwal. Turmeric (Curcuma longa) inhibits inflammatory nuclear factor (NF)- $\mathrm{BB}$ and $\mathrm{NF}-\mathrm{\kappa B}-$ regulated gene products and induces death receptors leading to suppressed proliferation, induced chemosensitization, and suppressed osteoclastogenesis. Molecular Nutrient Food Review. 56 (2012)454-465.

[12] S. MillsandK. Bone. Principles and Practice of Phytotherapy. Toronto, ON: Churchill Livingstone. (2000).

[13] R. I. Mohammad, A. Rubina, R. Obaidur, A. Mohammad, M. A. Akbar, M. Al-Amin K. D. Alam and F. Lyzu. In vitro antimicrobial activities of four medicinally important plants in Bangladesh. European Journal of Science Reviews. 39 (2010)199-206.

[14] A. Mukhopadhyay, N. Basu. And N. Ghatak. Antiinflammatory and irritant activities of curcumin analogues in rats. Agents Actions. 12 (2003) 508-515.

[15] M. Naganuma, A. Saruwatari, S. Okamura and H. Tamura. Turmeric and curcumin modulate the conjugation of 1naphthol in Caco-2 cells. Biological Pharm Bull. 29 (2006)1476-1479.

[16] P. S. Negi, K. G. Jayaprakasha, L. Jagan, M. Rao and K. K Sakariah. Antibacterial activity of turmeric oil: a byproduct from curcumin. Journal of Agricultural Food Chemist. 47 (2009)4297-4300.

[17] D. Rai, J. K. Singh, N. Roy and D. Panda. Curcumin inhibits FtsZ assembly: an attractive mechanism for its antibacterial activity. Journal of Biochemistry410 (2008)147-155.

[18] B. Surette, G. MichaelandL. Bonnie. Quorum sensing in Escherichia coli and Salmonella typhmurium. Proceedings of the National Academy of Sciences of the United States of America. National Academy of Sciences. 95 (2007) 7046-7050.
[19] K. Uthayarasa, K. Pathmanathan, J. P. Jeyadevan and E. C. Jeeyaseelan. Antibacterial activity and qualitative phytochemical analysis of medicinal plant extracts obtained by sequential extraction method. International Journal of Universal Pharmacy and Biosciences. 10 (2) (2010) 76-81.

[20] Y. Wang, L. Zhaoxin, W. Hao and L. Fengxia. Study on the antibiotic activity of microcapsule curcumin against food borne pathogens. International Journal of Food Microbiology. 136 (2009)71-76.

[21] R. K. Basniwal, H. S. Butter, V. K. Jain and N. Jain. Curcumin nanoparticles: preparation, characterization, and antimicrobial study. Journal of Agricultural Food Chemist. 59 (2011) 20562061.

[22] M. Ogata, M. Hoshi, S. Urano and T. Endo. Antioxidant activity of eugenol and related monomeric and dimertic compounds. Chem. Pharm. Bull, 48 (2002) 1467-1469.

[23] A. C. Amadioha. and V. I. Obi, V. Control of anthracnose disease of cowpea by Crymbopoyan citrates and Ocimumgratissimum. Acta. Phyto-pathol. Entomol. Hungenica 34 (1-2) (1999) 85-89.

[24] R. N. Okigbo and O. O. Ogbonnaya. Antifungal effects of two tropical plant extracts Occimumgratissimum and Afromummelegueta on post harvest yam Discoreaspp rot. African J. Biotech 9 (2006) 727-731.

[25] H. Jorge, B. Klein, G. Rudolf, F. Gerem, S. Micheal and M. Adele. Aromatic tumerone induces neural stem cell proliferation invitro and invivo. Stem cell Research and Therapy. (2014).

[26] A. J. Hou, Liu, H. Z. Yang, and H. D. Sun. Hydrolyzable tannins and related polyphenols from Eucalyptus globules. J. Asian Nat Prod . Res 2 (2000) 205-212.

[27] G. E. Trease and W. C. Evans. Pharmacognosy. 13thedition, Baailliere- Tindall. (1989) Pp 388, 396, 502-546.

[28] D. Sachdev, G. Amladi, S. Natraj, V. Baveja, S. Kharkar, U. Mahajan. And Khopkar. An outbreak of methicillin- resistant Staphylococcus aureus (MRSA) infection in dermatology indoor patients. Indian J. Dermatol. Venereol. Leprol. 69 (2003) 377-380.

[29] G. Ankur, M. Surabhi. and S. Rajendra. Evaluation of antimicrobial activity of Curcuma longa rhizome extract against Staphylococcus aureus. Biotechnol. Rep. 2015.

[30] C. Ishita, B. Kaushik, B. Uday, K. B. Ranajit. Tumeric and Curcumin: Biological actionsandMedicinal applications. Current Science. 87 (1) (2004). 44-53.

[31] R. Suvarna, S. S. Bhat and K. Sundeep. Antibacterial activity of Tumeric against Enterococcus faecalis- An Invitro Study. Int. J. Curr. Microbiol. App. Sci 3 (2) (2014). 498-504.

[32] G. Parveen and Jehan. B. Antimicrobial activity of turmeric extract and its potential use in food industry. J Food Sci Technol. 52 (4) (2013). 2272-2279.

[33] B. O. Ifesan. Antioxidant and antimicrobial properties of selected plant leaves. European J of Medicinal plants. 3 (3) (2013) 465-473.

[34] O. C. Nwinyi. N. S Chinedu. O. O Ajani. C. O. Ikpo and K. O Ogunniran. Antibacterialeffects of extracts of Ocimumgratissmum and Piper guineense on Escherichia coli and Staphylococcusaureus. Afri. J. Food Sci. 23 (2009). 77-81. 